\title{
Advice to a young hydrologist
}

\section{Keith Beven}

Lancaster Environment Centre, Lancaster University, Lancaster, UK and

Department of Earth Sciences, Uppsala University, Uppsala, Sweden

Some 15 years ago the Hydrological Processes Invited Commentaries were instigated by

Malcolm Anderson and Jeff McDonnell and I was one of the first to contribute a piece (Beven, 2000). Since then there have been many others, some of which have sunk without provoking much comment, and one of which instigated a succession of other commentaries. But this will, I suggest, be my last contribution in that I have recently formally retired from Lancaster University. It therefore seems a good opportunity to look to the future and offer some advice to any young hydrologists based on several decades of research experience.

Hydrology remains an important area of the environmental sciences. It is important both to human activities and as a driver for many other environmental processes. Hydrology will increasing act as a constraint on our activities, and will become an ever more important political issue, especially if managed in a risk accepting or conflict inducing way. It is easy to think of many well-published examples where this could happen or is already happening (fracking, potential for climate change, groundwater mining, trans-boundary issues, water footprint issues, ...). Hydrology is also, however,

This article has been accepted for publication and undergone full peer review but has not been through the copyediting, typesetting, pagination and proofreading process which may lead to differences between this version and the Version of Record. Please cite this article as doi: $10.1002 /$ hyp. 10879 
one of the inexact sciences and, given the limitations of what we can know about subsurface water pathways, it is likely to remain so. Thus, the most important piece of advice I can give is to be honest about those limitations, to yourself and to those who might be users of your research or your advice or your model outputs. That is not to say that you will always agree with other hydrologists who are also wanting to be honest about their science. That is the nature of the inexact sciences that are subject to epistemic uncertainties; sometimes we will just have to agree that there may be different explanations of the uncertain data, or different model projections of what the future might hold. Honesty to what you believe to be correct, logically argued and with proper account of relevant uncertainties, remains, however, essential.

Indeed, some of my most highly cited papers have been a simple result of trying to be honest, whether about the role of preferential flows in structured soils or the uncertainties in hydrological models. Those papers were not written to be highly cited (even if I did have the aim of persuading other hydrologists that these were important issues). That is something that has changed dramatically over the course of my career. I was really rather late in becoming aware of the significance of the $\mathrm{h}$ index and other measures of performance based on citations. As one of the editorial board of Hydrological Processes I have also had to be become concerned with Impact Factors and the various ways of increasing them. Nearly 30 years ago when the market research for the new journal called Hydrological Processes was being done, I suggested to Malcolm Anderson that we perhaps did not need a new journal as there were not enough good papers to go around the existing journals already. 
How wrong I was it seems. Not only do we now have 29 volumes of Hydrological Processes which expanded to 26 issues and over 4000 pages per year but an equal expansion of those journals that pre-dated HP and an apparent inexorable increase in new hydrologically related journals. Scientific publishing is a booming industry and an opportunity for profit (including some of the new open source journals). Should we still worry about there not being enough good papers to go round?

I think we should and have suggested in editorial meetings that the number of papers in HP should be reduced with a view to upgrading the quality of papers published.

Recently the rejection rate for HP has gone up significantly. This is in part because the editorial board have been more rigorous about papers that are not in scope for the journal (it really is surprising how many authors submit papers that are hydrological in content, but do not refer to hydrological processes). But if papers get past that first barrier, reducing the number of papers accepted is difficult when, in the peer review system, referees suggest that many papers represent worthwhile contributions to "improving our understanding of hydrological processes" (as stated in the objectives of HP). It is also difficult when everybody understands that the career of a young researcher is highly dependent on getting papers in international journals with good impact factors and later promotions, job opportunities and research grant success will continue to depend on the track record of publications and $\mathrm{h}$ index, despite all the criticisms that are made of this type of rather crude evaluation. There are more and more ways that an early career researcher can use to get their work noticed such by networking on Research Gate, LinkedIn or even Facebook. Research is evolving to be a highly competitive rather than collaborative activity (while recognising that selective collaborations can be a good way of increasing competitiveness and success). 
I have myself published too many modelling papers, arguably far too many, for some of those very reasons mentioned above. I would not make any claim that all of those papers have greatly advanced our understanding of hydrological processes. I have, however, been fortunate in having quite a number of articles that have been highly cited (Koutsoyiannis and Kundzewicz, 2007). Not all the citations have been positive, of course, many were from other authors wanting to point out how wrong I was but that is the nature of scientific debate, debate that is needed to make progress in a thoughtful way. There will soon be others who are more highly cited, particularly those working in the domain of global change and its hydrological impacts.

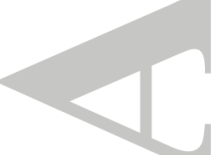

That is something else that has changed in the last decade. Everyone is concerned with impact. The 2014 UK Research Evaluation Framework, which scores and ranks every academic in the UK, had a whole section devoted to impact case studies. More and more research funding organisations require that impacts of the research, and their dissemination, be part of the proposal (actually before the research is done of course). But in the water area, having impact requires addressing the needs of policy makers in water management, with significant inertia to making change. The safe area in this respect is addressing future change. Policy makers want to know about the future. They want evidence on which to base their policy (or even better, evidence that supports their proposed policy) - and would like that evidence to be much more certain than is usually possible. It is safe (and comfortable) to promise model results to provide that evidence and that will therefore have policy impacts. Methods for doing so have become almost a self-generating industry. 
The problem is that much of this work is pretty irrelevant, when the models that provide the projections and estimates the impact of future change are not adequate.

This is glossed over within the industry by avoiding post-audit analyses in the style of Konikow and Bredehoeft (1992), because the boundary conditions for model simulations always turn out to be different (and the current generation of models is, of course, better than when those projections were made). What reviews of decadal projections have been done have been from outside the climate community (e.g. Fildes and Kourentzes, 2011; Suckling and Smith, 2013). As hydrologists we know, only too well, that there are important mismatches between our perceptual models of processes controlling flow, residence times, and water quality in the field, and the way those processes are represented in our models. Those limitations can be compensated, to some extent, by allowing for uncertainties, but are fundamentally due to lack of knowledge. The uncertainties are epistemic and, again, we should be honest about them and the capabilities of our models. There is much still to be done about testing catchment models as hypotheses about how catchments work and rejecting them when necessary (e.g. Beven, 2015).

Because rejection is a good thing (-) for both models and for those papers that you were hoping were going to be accepted by a journal at first submission and then become highly cited. This is because if the rejection is justified it means that you need to do better. I stressed this in a workshop on writing a benchmark paper in hydrology for the EGU Young Hydrologists at the 2015 Assembly in Vienna. Not many people will know that I have had many rejected papers throughout my career (but see ${ }^{1}$ ). The second

\footnotetext{
${ }^{1}$ http://iahs.info/About-IAHS/Competition--Events/International-HydrologyPrize/International-Hydrology-Prize-Winners/KBeven/
} 
paper I ever submitted (the Topmodel paper of Beven and Kirkby, 1979) was rejected by Eamonn Nash, the editor of the Journal of Hydrology, as of too local an interest (in a very short letter without any other referee comments $:$ ). Fortunately it was accepted by Hydrological Sciences Bulletin and became my most highly cited paper (;)).

The lesson is not to be too downhearted if you get a rejection. If the referees did not think it was worth publishing, then either they had a good reason for doing so (in the case of the Topmodel paper it was because the manual topographic analysis in the days before digital elevation data was far too time-consuming for any practical engineering application) or because the author has not got the message across well enough. If the referees do not convince you otherwise and you believe that what you are doing is worthwhile then the latter is something you can do something about in creating a new version.

Remember that when you are asked to do reviews yourself. If you do not think a paper is sufficiently interesting, novel, or logical in its analysis, then say so - but try to do so in a constructive way (even if you have received less than constructive reviews yourself). There are lots of well-documented problems with the peer review system but it can work well if used constructively and my experience suggests you will learn more about presenting your own work in providing constructive reviews. However, if you do find that you have an article of your own that is still upsetting some referees and you believe in what you are doing then it might be the case that you could be changing the way things might be done in future (and consequently have a highly cited paper - this is the case of my GLUE and macropore papers). Breaking the normal paradigm will always involve rejections. But remember that in presenting your work you need to decide on 
what story to tell, and that you should present that story, not just to report what you have done, but to try and influence the rest of the community. That is the way real advances will be made.

The story you wish to tell, however, may not always be to everyone's liking. It is not always possible to come to positive conclusions. In trying to be honest in pointing out some of the limitations of our science (for example, in discussing the limitations of distributed models, or in rejecting all the models tried as not giving acceptable results, or in suggesting that some hydrological data might be disinformative in model testing, or being sceptical about the use of formal statistical likelihoods in model evaluation, ....), I have sometimes been accused of not being sufficiently positive or even of undermining the science (see Beven, 2006, 2008). But as with paper rejections, a recognition of limitations should not be the end of the story, but the starting point for doing better, and where I have been forced to be critical of some of the work that has been done in hydrological modelling, it has usually been a spur to new research. A case in point is the comment I wrote on the first SHE model papers that appeared in Journal of Hydrology in 1986. This comment was first "lost" and then, some months later, rejected by Jim McCullough as editor of Journal of Hydrology, on the basis that it was too long and would be better presented as a paper. But to write it up as a paper, I felt I had to find a way ahead, resulting in one of the first papers to suggest that we really had to be more explicit about assessing the uncertainties associated with hydrological models and distributed models in particular (see Beven, 1989). The debate is still on-going see the discussion of hyperresolution models in Wood et al; (2011) and Beven et al. (2015). And I sometimes do try to be as positive as possible (at least under the influence of others, see Juston et al., 2012). 
But, you have to get people to read your paper before you can have any influence (or get any citations). These days that means having a good title, because the first thing that other hydrologists will generally see of your paper will be as a title in a Contents Alert. So the title has to be good enough to draw the reader in enough to at least click on the title and bring up the abstract. It is, of course, becoming more difficult to get noticed. There are more and more journals, containing more and more papers, and people receive more and more Contents Alerts. Sheer pressure of time means that people will be selective about which alerts they sign up for, let alone read, so that is one reason for trying to get your best papers published in a journal with a higher impact factor (such as Hydrological Processes, naturally). Be aware, however, those journals are also likely to have the highest rejection rates, so make sure you have a good story to tell and that you try to think about all the questions that the referees might ask before you submit the paper. And as I said at the EGU workshop, the very first question many referees ask is has my own (always highly relevant, of course) paper been cited. It is therefore important that you have a good understanding of the literature in the area, and do not just rely on a superficial computer keyword search in preparing the background for your work.

Being now of pensionable age perhaps allows me to also reflect on the ways hydrological research has changed and is changing. I have no nostalgia for the days when hydrological data were recorded on paper charts, computer programs were stored on punched cards, and we had no means of investigating spatial patterns using remote sensing, or the subsurface using geophysics, or residence times using environmental tracers. On the other hand, some things do not seem to have progressed 
too much. There are still discussions about finding optimal models, there are still deterministic predictions of hydrological futures, there are still models based on the Darcy-Richards equation, the Manning equation and SCS curve numbers, often applied quite inappropriately (I should perhaps include many applications of Topmodel here since it is clear that in many applications users have not considered whether the rather strong assumptions are appropriate or not, see also Beven, 2014a). This suggests therefore that we still need some rather fundamental process research (particularly in putting flow and transport into a consistent coherent framework that includes the effects of heterogeneities and preferential flows, see e.g. McDonnell and Beven, 2014). And we need that research to address the scaling issues so that any theory can be applied at the scales needed for practical water management problems. I think the concepts of co-evolution and self-organisation are interesting to explore, in this respect, even if I doubt if they will ultimately prove useful (see Beven, 2014b). The ubiquitous effects of humans, and the lack of past information on changing boundary conditions will, I think, be too strong a constraint.

It is also becoming far more difficult for a young hydrologist to get noticed in terms of either getting papers published or being successful in generating research funding (even if some funding agencies have small programmes directed specifically at early career researchers). It is difficult to know what advice to offer in this respect. In the UK now, there are limits on the numbers of research proposals that can be submitted by any University based on past success rates. This means that young researchers are competing with more established scientists internally (including from other Departments) even before being allowed to submit a proposal externally. One strategy here is to collaborate with more established researchers, at the risk of not being seen to 
establish an independent reputation. Another is to make use of those small early research grants to demonstrate independence in a particular focus area. In doing so, however, focus is important. Do not spread your talents too thinly but try to build up a core of expertise in an area of innovative research that other will, hopefully, increasingly recognise.

I would suggest, however, that there are future dangers for hydrological science here. Given limited resources it is much more efficient to produce papers based on modelling results than on field experimentation, especially experimentation that relies on costly equipment at many sites and sample analyses at many times. Even in HP, a quick look at the papers for 2014 reveals that more than half of the published papers were primarily concerned with modelling and much less with field or laboratory experiments. But hydrological science is measurement technique dependent. Each real advance in the science during my own research career has been a function of new experimental techniques that have then been exploited by modellers. I can think of few real insights that have been the result of new theoretical developments or modelling results. And yet it appears as if it is going to be more difficult in future to get experimental and fieldwork supported. Perhaps it needs a community effort amongst young hydrologists to persuade those with established reputations that there is a problem here and that some leadership is required to decide on priorities for new types of measurements and their applications. There have been some success stories of course (e.g. GRACE, SWOT, COSMOS, FLUXNET, BIOSPHERE 2,....) but we need more. Where is that method of directly measuring discharge in an arbitrary channel, or of directly measuring integrated storage at field plot or hillslope scales, or improved methods of measuring 
evapotranspiration over a catchment area rather than at a point? Such methods would have a direct impact on theory.

One area of focus that cannot be ignored (but is often neglected in models) is the impact of humans on catchment systems (even if for much of my own research I have managed to do so). The Panta Rhei initiative on the hydrological impacts of change, including the effects of man as sociohydrology, should be supported strongly by all hydrologists (e.g. Montanari et al., 2013). As with the previous prediction in ungauged basins (PUB) initiative, or the prediction of global change, it may seem to be an impossible problem (or at least to involve large epistemic uncertainties that are difficult to constrain) but some progress in sociohydrology should surely be possible. What we should be wary of, as both researchers and referees on papers in this area, is reporting the illusion of progress. We do not need more hypothetical studies of sociohydrological interactions that are not firmly rooted in real practical applications. Hypothetical studies are much quicker and easier to produce but I would suggest that real cases studies will be, as ever in these inexact sciences, of greater value.

I have written elsewhere that I think this will in part be achieved by having greater interaction with stakeholders in catchments by making use of models of everywhere (Beven, 2003, 2007; Beven and Alcock, 2012; Beven et al., 2015). The most important aspects of models of everywhere are being open and honest about the assumptions that are being made, and being open to the suggestions from stakeholders that the model is wrong. In this way modelling will become much more of a learning process. In this framework, there really are benefits in being realistic about modelling uncertainties since it means that the modeller is much less likely to be wrong. If, however, there are 
still reasons to reject based on local knowledge, then you will have learned something. I would hope to see some young hydrological modellers take this approach forward with enthusiasm because again I think we have much to learn from such rejections. While we await the arrival of new measurement techniques that provide hydrologically useful information at hydrologically useful scales, that is how you will progress our science in future. Go for it!

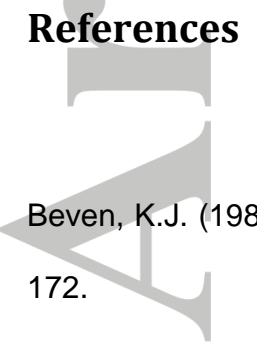

Beven, K J (2000), On model uncertainty, risk and decision making, Hydrological Processes (HPToday), 14, $2605-2606$

Beven, K J, 2003, On environmental models of everywhere using the GRID, Hydrological Processes (HPToday), 17, 171-174.

Beven, K J, 2006, On undermining the science?, Hydrological Processes (HPToday), 20, 3141-3146.

Beven, K J, 2007, Working towards integrated environmental models of everywhere: uncertainty, data, and modelling as a learning process. Hydrology and Earth System Science, 11(1), 460-467.

Beven, K J, 2008, On doing better hydrological science, Hydrological Processes (HPToday), 22: 3549-3553. Beven, K J, 2014a, BHS Penman Lecture: "Here we have a system in which liquid water is moving; let's just get at the physics of it" (Penman 1965). Hydrology Research, 45(6), 727-736, DOI: $10.2166 / \mathrm{nh} .2014 .130$

Beven, K J, 2014b, What we see now: event-persistence in predicting the responses of hydro-ecogeomorphological systems? Ecological Modelling, http://dx.doi.org/10.1016/i.ecolmodel.2014.07.019

Beven, K J., 2015, EGU Leonardo Lecture: Facets of Hydrology - epistemic error, non-stationarity, likelihood, hypothesis testing, and communication. Hydrol. Sci. J. $10.1080 / 02626667.2015 .1031761$ 
Beven, K. J. and Alcock, R., 2012, Modelling everything everywhere: a new approach to decision making for water management under uncertainty, Freshwater Biology, 56, 124-132, doi:10.1111/j.13652427.2011.02592.x

Beven, K J, Cloke, H., Pappenberger, F, Lamb, R and Hunter, N, 2015. Hyperresolution information and hyperresolution ignorance in modelling the hydrology of the land surface. SCIENCE CHINA Earth Sciences, 58 (1): 25-35.

Beven, K.J., Kirkby, M.J. (1979), "A physically-based variable contributing area model of basin hydrology'. Hydrological Sciences Bulletin, 24(1), 43-69.

Fildes, R., \& Kourentzes, N. (2011). Validation and forecasting accuracy in models of climate change. International Journal of Forecasting, 27(4), 968-995.

Juston, J. M., A. Kauffeldt, B. Q. Montano, J. Seibert, K. J. Beven and I. K. Westerberg, 2012, Smiling in the rain: Seven reasons to be positive about uncertainty in hydrological modelling, Hydrological Processes (HPToday), DOI: 10.1002/hyp.9625

Konikow L. F. and Bredehoeft J. D. Groundwater models cannot be validated. Advances in Water Resources, 15:75-83, 1992.

Koutsoyiannis, D. and Kundzewicz, Z. W., 2007 Editorial: Quantifying the Impact of Hydrological Studies, Hydrological Sciences Journal, 52(1), 3-17.

McDonnell, J J and Beven, K J, 2014, Debates-The future of hydrological sciences: A (common) path (1) forward? A call to action aimed at understanding velocities, celerities, and residence time distributions of the headwater hydrograph, Water Resour. Res., 50, doi:10.1002/2013WR015141.

Montanari, A., Young, G., Savenije, H. H. G., et al., (2013). “Panta Rhei-Everything Flows”: Change in hydrology and society-The IAHS Scientific Decade 2013-2022. Hydrological Sciences Journal, $58(6), 1256-1275$.

Suckling, E. B., \& Smith, L. A. (2013). An Evaluation of Decadal Probability Forecasts from State-of-the-Art Climate Models*. Journal of Climate, 26(23), 9334-9347. 